\title{
Effect of evodiamine and berberine on the interaction between DNMTs and target microRNAs during malignant transformation of the colon by TGF- $\beta 1$
}

\author{
CHAO HUANG, HONG LIU, XIU-LI GONG, LI-YUN WU and BIN WEN
}

Pi-Wei Institute, Guangzhou University of Traditional Chinese Medicine, Guangzhou, Guangdong 510000, P.R. China

Received March 9, 2016; Accepted April 7, 2016

DOI: $10.3892 /$ or.2017.5379

\begin{abstract}
The tissue microenvironment functions as a crucial player in carcinogenesis, and transforming growth factor- $\beta 1$ (TGF- $\beta 1$ ) within the microenvironment stimulates the formation of neoplasms. Using an in vitro model of malignancy induced by TGF- $\beta 1$, we assessed the effect of evodiamine and berberine on the interaction between DNA methyltransferases (DNMTs) and target microRNAs (miRNAs) in the model. Colon tissues from neonatal rats 7 days of age were cultured and malignancy was induced by TGF- $\beta 1$ in vitro for $48 \mathrm{~h}$, and then the tissues were respectively treated with evodiamine and berberine for $24 \mathrm{~h}$. Morphological alteration of tissues was observed by an inverted microscope, histological structures were observed using hematoxylin and eosin staining, and the expression levels of DNMTs and targeted miRNAs screened by bioinformatics software combined with Gene chip analysis in our previous study were detected by immunohistochemistry and quantified by real-time PCR. Twenty-four hours after treatment with TGF- $\beta 1$, expression levels of DNMT1, DNMT3A, DNMT3B and miR-152 (target DNMT1), miR-429 (target DNMT3A) and miR-29a (target DNMT3A/3B) were markedly decreased; however, after $48 \mathrm{~h}$, the expression levels of DNMT1 and DNMT3A were significantly increased, but their target miRNAs were still decreased. After treatment with a DNMT inhibitor (5-Aza-dC), expression levels of the miRNAs were increased to a larger extent, but did not reach normal levels. After treatment with berberine and evodiamine for $24 \mathrm{~h}$, respectively, increased expression of DNMT1, DNMT3A, DNMT3B and miR-152, miR-429, miR-29a was noted. In conclusion, the results of the present study suggest that miRNAs can also be post-transcriptionally regulated by their corresponding DNMTs and that berberine and evodiamine regulate the expression of these genes, which provides
\end{abstract}

Correspondence to: Professor Bin Wen, Pi-Wei Institute, Guangzhou University of Traditional Chinese Medicine, Guangzhou, Guangdong 510000, P.R. China

E-mail:wenbin@gzucm.edu.cn

Key words: colorectal cancer, carcinogenesis, epigenetics, tumor microenvironment, evodiamine, berberine early epigenetic evidence for the prevention and therapy of colorectal cancer.

\section{Introduction}

At present, colorectal cancer (CRC) is considered to be a major health issue due to its marked morbidity and mortality in humans (1). Of course, studies concerning the underlying mechanisms involved in colorectal carcinogenesis and drug development are unceasing. Genetic alterations have provided a molecular mechanism for colon carcinogenesis and potential targets for anticancer durgs; however, the results obtained in preclinical studies remain unsatisfactory $(2,3)$. Recently, epigenetic alterations, which are defined as heritable changes in gene expression resulting from mechanisms instead of changes in underlying DNA sequences, are believed to contribute to the formation and development of CRC. The best understood epigenetic mechanisms include DNA methylation, histone modifications and microRNAs (miRNAs, miRs) (4). DNA methylation events in mammalian cells are mainly caused by two major types of enzymatic activities, namely, maintenance methylation by DNA methyltransferase (DNMT)1 and de novo methylation by DNMT3A and DNMT3B. miRNAs can regulate gene expression by degradation of target mRNAs; however, whether these miRNAs are in turn regulated by target genes remains elusive.

The initiation of colon cancer cannot be completely explained from the viewpoint of genetic and family history. Robust in vitro and in vivo evidence indicates that microenvironmental factors are involved in the onset of CRC (5). The extremely complex tumor microenvironment (TME) consists of numerous elements including extracellular matrix (ECM) components, such as laminin and collagen, vascular endothelial growth factor (VEGF), transforming growth factor (TGF), glucose and varying concentrations of oxygen (6), as well as various types of cells, such as tumor, endothelial and epithelial cells, fibroblasts, and immune and mesenchymal stem cells (7). Cancer development and progression including initiation, proliferation, invasion, metastasis and therapeutic resistance are driven by increasingly accumulated genetic and epigenetic alterations in cancer cells themselves as well as constructional changes in their microenvironment (8). Stromal cells and the ECM of the microenvironment can serve as a significant regulator of cancer initiation, growth and progression $(9,10)$. Fifteen 
years ago, Hanahan and Weinberg concluded that cancer cells do not exist in isolation and that tumors are complex collaborations between multiple cell types (11), implying that an optimal microenvironment is required for cancer progression. TGF- $\beta$ is an important component of the microenvironment and is secreted by stromal cells and tumor cells serving as a crucial player in tumor initiation (12). TGF- $\beta$ has a dual function. It is a suppressor in early tumorigenesis but a promoter at the later stage since its continued elevation or perturbation of its signaling promotes malignant transformation. However, at the microenvironment level, the TGF- $\beta$ pathway facilitates the generation of an optimal microenvironment in favor of tumor growth and metastasis throughout all the steps of carcinogenesis (13). In light of the above findings, in the present study, we designed a model of malignant transformation induced by transforming growth factor- $\beta 1$ (TGF- $\beta 1$ ) to analyze the relationship between DNA methyltransferases (DNMTs) and target miRNAs and the intervening effect of evodiamine and berberine on this interaction.

\section{Materials and methods}

Experimental animals and reagents. Neonatal rats, 7 days of age, were purchased from the Experimental Animal Center of Guangdong Province. Dulbecco's modified Eagle's medium (DMEM) (Gibco, Grand Island, NY, USA), berberine chloride (Sigma, St. Louis, MO, USA), evodiamine (Wako, Tokyo, Japan), 5-Aza-dC (Sigma-Aldrich, St. Louis MO, USA), D-Hank's solution, fetal bovine serum (FBS), penicillin-streptomycin (all from Gibco), TGF- $\beta 1$ (PeproTech, Inc., Rocky Hill, NJ, USA), bovine pituitary extract (Sigma) were used. MMLV reverse transcriptase, RNA enzyme inhibitor (Epicentre, Madison, WI, USA), 2X PCR Master Mix (SuperArray, Frederick, MD, USA), 10X RT buffer solution (200 mM KCl, 5 mM DTT, 250 mM Tris-HCl, pH 8.3, 40 mM $\mathrm{MgCl}_{2}$; Epicentre), and $2.5 \mathrm{mM}$ dNTP mix (2.5 mM dATP, $2.5 \mathrm{mM}$ dCTP, $2.5 \mathrm{mM}$ dGTP and $2.5 \mathrm{mM}$ dTTP; HyTest Ltd., Turku, Finland) were used.

Medium preparation. Basic medium preparation included $10 \mathrm{ml}$ FBS, bovine pituitary extract $5 \mathrm{ng} / \mathrm{ml}$, penicillin-streptomycin $100 \mathrm{U} / \mathrm{ml}$. A TGF- $\beta 1$ stock solution $(1,000 \mathrm{ng} /$ $\mathrm{ml})$ was prepared by dissolving $1 \mu \mathrm{g}$ TGF- $\beta 1$ in $1 \mathrm{ml}$ sterile double distilled water and maintained at $-20^{\circ} \mathrm{C}$. The medium containing TGF- $\beta 1$ was namely the diluted TGF- $\beta 1$ stock solution with basic medium $(10 \mathrm{ng} / \mathrm{ml})$. A berberine chloride stock solution $(10,500 \mu \mathrm{M})$ was obtained by dissolving $21.4 \mathrm{mg}$ berberine in $5 \mathrm{ml}$ double distilled water and sterilized with $0.22-\mu \mathrm{m}$ filter membrane, and diluted to $105 \mu \mathrm{M}$ with basic medium when used. Evodiamine $(2.3 \mathrm{mg}$ ) was dissolved in dimethyl sulfoxide (DMSO) and processed with ultrasonic vibrating to prepare a $1,500 \mu \mathrm{M}$ stock, and diluted with basic medium to a working concentration $(15 \mu \mathrm{M})$. The medium containing 5-Aza-dC $(2.5 \mu \mathrm{M})$ was from the diluent of the $250 \mu \mathrm{M}$ stock with basic medium.

Tissue culture and treatment. Since our previous study found that colon tissue from neonatal rats of 7 days of age display robust vitality and were easily cultured (data not provided), we used the tissues from these rats as our in vitro model in the

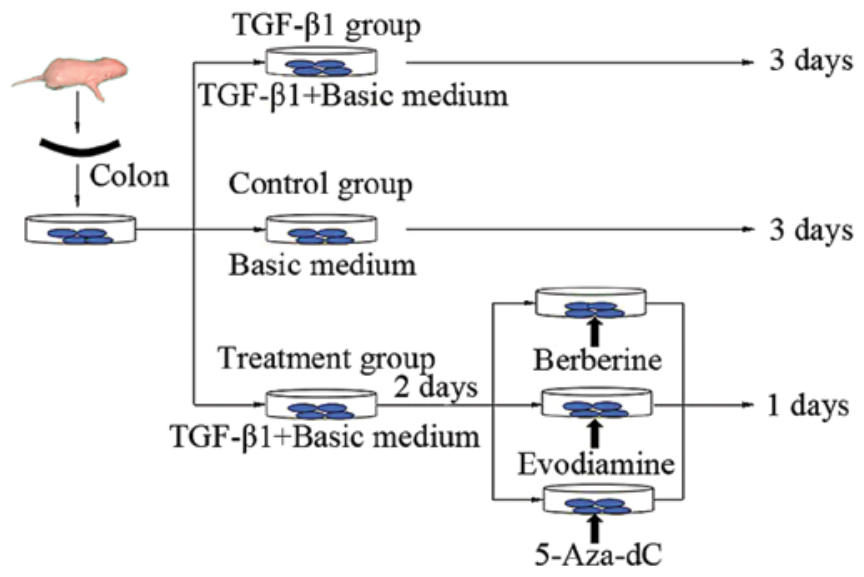

Figure 1. Flow chart of the colon tissue culture and canceration induction by TGF- $\beta 1$.

present study. The rats were sacrificed by cervical spine dislocation and were immediately dissected in a sterile console to obtain the colon tissues. The tissues were immediately washed in cold D-Hank's cleaning solution, followed by longitudinal dissection and repeated washings with D-Hank's to eliminate mesentery, blood clots, fatty tissues and debris in the intestine. Afterwards, the cleaned colon tissues were cut into $1-2 \mathrm{~mm}^{3}$ tissue blocks, and then plated into a 6 -well plate. To note, a $0.5-\mathrm{cm}$ interval between each block was considered to be suitable. After redundant fluid around the tissue blocks was drained, the plates were cultured in an incubator with $5 \% \mathrm{CO}_{2}$ at $37^{\circ} \mathrm{C}$ until the redundant fluid around the blocks became dry. The plates were then overturned, the medium was added and the culturing was continued under the previous conditions. In the present study, the tissues were divided into 3 groups: TGF- $\beta 1$, control and treatment groups, which were further divided into the berberine, evodiamine and 5-Aza-dC groups. The control group was cultured with basic medium for 3 days, and the TGF- $\beta 1$ group was cultured with medium containing TGF- $\beta 1$ of $10 \mathrm{ng} / \mathrm{ml}$ for 3 days, while the treatment groups were first cultured with medium of $10 \mathrm{ng} / \mathrm{ml}$ TGF- $\beta 1$ for 2 days, and then berberine chloride, evodiamine and 5-Aza-dC were respectively added and were again cultured for $24 \mathrm{~h}$ (Fig. 1). All tissue samples were collected after they were cultured for 24,48 and $72 \mathrm{~h}$, and were then frozen at $-80^{\circ} \mathrm{C}$ for RT-PCR detection.

Hematoxylin and eosin $(H \& E)$ staining for observation of the histological structures in the colon tissues. The colon tissues were cultured and fixed with $4 \%$ paraformaldehyde, and then paraffin-embedded samples were cut into $4-\mu \mathrm{m}$ sections. After a 10- and a 3-min treatment with dimethylbenzene and ethanol, respectively, the slices were stained with hematoxylin for $10 \mathrm{~min}$ and subsequently $0.5 \%$ eosin for $3 \mathrm{~min}$, and then again treated with ethanol. The slices were sealed with neutral gum and observed for obtaining images using an inverted phase contrast microscope.

Immunohistochemistry (IHC). Samples fixed with 4\% paraformaldehyde for 24-48 h were dehydrated, permeabilized and embedded with paraffin. Paraffin-embedded slides ( $4 \mu \mathrm{m})$ 
Table I. Primer sequences of the DNMTs and microRNAs for RT-PCR.

\begin{tabular}{|c|c|c|}
\hline Gene & & '-directional primer sequences 5'-3' \\
\hline \multicolumn{3}{|l|}{ DNMTs } \\
\hline GAPDH (internal control) & $\begin{array}{l}\text { Forward } \\
\text { Reverse }\end{array}$ & $\begin{array}{l}\text { 5'-ggtcggtgtgaacggatttgg-3' } \\
\text { 5'-gtagaccatgtagttgaggtc-3' }\end{array}$ \\
\hline DNMT1 & $\begin{array}{l}\text { Forward } \\
\text { Reverse }\end{array}$ & $\begin{array}{l}\text { 5'-atggcttaacagaaaaggagtg-3' } \\
\text { 5'-gccaggtagccttcctcagacaa-3' }\end{array}$ \\
\hline DNMT3A & $\begin{array}{l}\text { Forward } \\
\text { Reverse }\end{array}$ & $\begin{array}{l}\text { 5'-ggcactcgetgggtcatgtgg-3' } \\
5^{\prime} \text {-gctggccacctggaggacttc-3' }\end{array}$ \\
\hline DNMT3B & $\begin{array}{l}\text { Forward } \\
\text { Reverse }\end{array}$ & $\begin{array}{l}\text { 5'-agtgggtatgaggactgtatcat-3' } \\
\text { 5'-agactggctctgtgcagattg-3' }\end{array}$ \\
\hline \multicolumn{3}{|l|}{ microRNAs } \\
\hline U6 (internal control) & $\begin{array}{l}\text { Forward } \\
\text { Reverse }\end{array}$ & $\begin{array}{l}\text { 5'-gcttcggcagcacatatactaaaat-3' } \\
5^{\prime} \text {-cgcttcacgaatttgcgtgtcat-3' }\end{array}$ \\
\hline microRNA-29a & $\begin{array}{l}\text { Forward } \\
\text { Reverse }\end{array}$ & $\begin{array}{l}\text { 5'-tgactgatttcttttggtgttc-3' } \\
\text { 5'-gtcgtatccagtgcagggtccgaggtattcgcactggatacgacctgaa-3' }\end{array}$ \\
\hline microRNA-152 & $\begin{array}{l}\text { Forward } \\
\text { Reverse }\end{array}$ & $\begin{array}{l}\text { 5'-aggttctgtgatacactccg-3' } \\
\text { 5'-gtcgtatccagtgcagggtccgaggtattcgcactggatacgacagtcg-3' }\end{array}$ \\
\hline microRNA-429 & $\begin{array}{l}\text { Forward } \\
\text { Reverse }\end{array}$ & $\begin{array}{l}\text { 5'-tgtaatactgtctggtaatgc-3' } \\
\text { 5'-gtcgtatccagtgcagggtccgaggtattcgcactggatacgacacggc-3' }\end{array}$ \\
\hline
\end{tabular}

DNMTs, DNA methyltransferases.

were deparaffinized by dimethylbenzene for $10 \mathrm{~min}$ and were incubated with $5 \% \mathrm{FBS}$ at room temperature for $10 \mathrm{~min}$. Antigen retrieval was performed separately using moderate heat-induced antigen retrieval two times in a microwave oven. IHC was performed using rabbit monoclonal antibodies against $\alpha$-SMA, Crumbs 3 and E-cadherin. Primary antibodies were diluted in Antibody Diluent (Beyotime, Wuhan, China) to the indicated optimal dilutions of 1:100 for Crumbs3; 1:50 for E-cadherin; and 1:1,000 for $\alpha$-SMA. The slides were stained with DAB staining used as the chromogen for the optimal time, and then hematoxylin for $1 \mathrm{~min}$. Optical density (OD) values of the positive immune product for each group were obtained by pathological analysis software IPP 6.0.

Detection of DNMT and miRNA expression by real-time PCR. To extract the total RNA of each sample, the collected samples were fully ground into a powder-like material in liquid nitrogen, and a certain amount of powder was added to $1 \mathrm{ml}$ of TRIzol, and RNA concentration was performed using isopropanol. In addition, the RNA quality and quantity in the samples were confirmed through ultraviolet absorption measurement and denatured agarose gel electrophoresis. To minimize variation, all RNA samples from a single experiment were reversetranscribed simultaneously according to the instructions of the manufacturer. The RT reaction mix contained a total of $800 \mathrm{ng}$ RNA, $2 \mu \mathrm{l}$ of 10X RT buffer, $2 \mu \mathrm{ldNTP}(2.5 \mathrm{mM}$ each), 0.2 $\mu \mathrm{l}$ MMLV reverse transcriptase (200 U/ $\mu \mathrm{l}), 0.3 \mu \mathrm{l}$ RT-specific primer $(1 \mu \mathrm{M})$ and $0.3 \mu \mathrm{l}$ of RNase inhibitor $(40 \mu /$ $\mu \mathrm{l})$ in $20 \mu \mathrm{l}$ RNase-free water. The following bi-directional primers of DNMTs and miRNAs were designed using primer design software Primer 5.0 (Bio-Rad, Hercules, CA, USA) and were used for RT-PCR (Table I). Thermal cycling was performed using 40 cycles at $95^{\circ} \mathrm{C}$ for $10 \mathrm{~min}, 95^{\circ} \mathrm{C}$ for $10 \mathrm{sec}$ and $60^{\circ} \mathrm{C}$ for $60 \mathrm{sec}$ using CFX96 (Bio-Rad). Each PCR of the RNA samples from 3 independent experiments was repeated 3 times, and the average median threshold cycle values were used for analysis owing to the random error of each sample. Control genes GAPDH and U6 were respectively used for normalization comparison of DNMTs and miRNAs in the samples, and the relative expression level was obtained by comparative CT method in which the fold change of the gene was calculated by $2^{-\Delta \Delta \mathrm{Ct}}$.

Statistical analyses. All data were processed by statistical software SPSS 19.0 (SPSS Inc. Chicago, IL, USA). The RT-PCR results are presented as mean \pm SEM. One-way ANOVA analysis was adapted to accomplish the comparison among 3 groups. Level of significance $\alpha$ was 0.05 , and a probability value $\mathrm{P}<0.05$ was considered to indicate a statistically significant result.

\section{Results}

Morphological alterations during tissue culture. As shown in Fig. 2, out-migration of cells in the tissues was found in the process of culture, and the cells revealed a paved stonelike proliferation from the tissue edge towards the outside. Out-migrated cells at the edge of the tissue were increasingly dense following TGF- $\beta 1$ treatment than that noted in cells treated with basic medium revealing sporadically distribution 


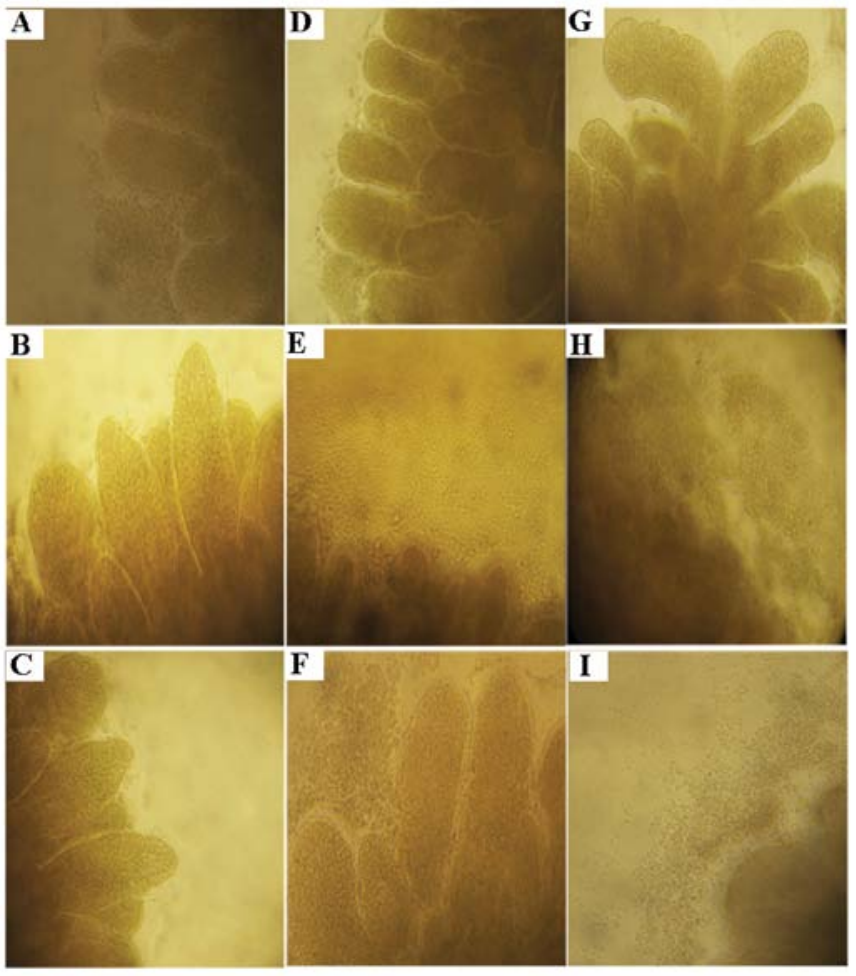

Figure 2. Morphological alterations of colon tissues cultured for the indicated times were observed through inverted microscope (magnification, $\mathrm{x} 250$ ). (A-C) Representive control tissues cultured for 24,48 and $72 \mathrm{~h}$, respectively. (D-F) Representive tissues treated with TGF- $\beta 1$ for 24,48 and $72 \mathrm{~h}$, respectively. (G-I) Representive tissues treated with evodiamine, berberine and 5-Aza-dC for $24 \mathrm{~h}$, respectively.

of cells around the tissue, suggesting that TGF- $\beta$ markedly promoted cell proliferation. In contrast, the numbers of cells at the edge of the tissues treated respectively with berberine, evodiamine and 5-Aza-dC were decreased to a varied extent, namely, the cytostatic effect of evodiamine was highly obvious, which was followed by berberine, and that of 5-Aza-dC was the weakest, indicating that these drugs inhibited the cell growth induced by TGF- $\beta 1$ through various mechanisms which are likely to be associated with epigenetics.

TGF- $\beta 1$ stimulates histological changes in the colon tissues as determined by $H \& E$ staining. After a 48 -h culture, various sizes and larger gaps between cells were observed in tissues treated with TGF- $\beta 1$, compared to that noted in the control revealing a paved stone-like epithelium tightly arranged. Our $\mathrm{H} \& \mathrm{E}$ staining revealed that epithelial structures were tightly arranged in the mucosa involving more chromatin in the nucleus (detected by deep H\&E staining, as shown in Fig. 3A and B) in the control tissues. However, the epithelial cells were loosely arranged in the tissues exposed to TGF- $\beta 1$ presenting changes of phenotype including many fibroblast-like cells as demonstrated by high expression of $\alpha$-SMA (Fig. 3C and D), a marker of fibroblasts.

Expression of Crumbs3, E-cadherin and $\alpha$-SMA by IHC and $R T-P C R$. TGF- $\beta 1$, a pleiotropic cytokine, is primarily released from tumor cells and stroma in the tumor microenvironment (TME) and promotes the creation of a pro-TME and functions
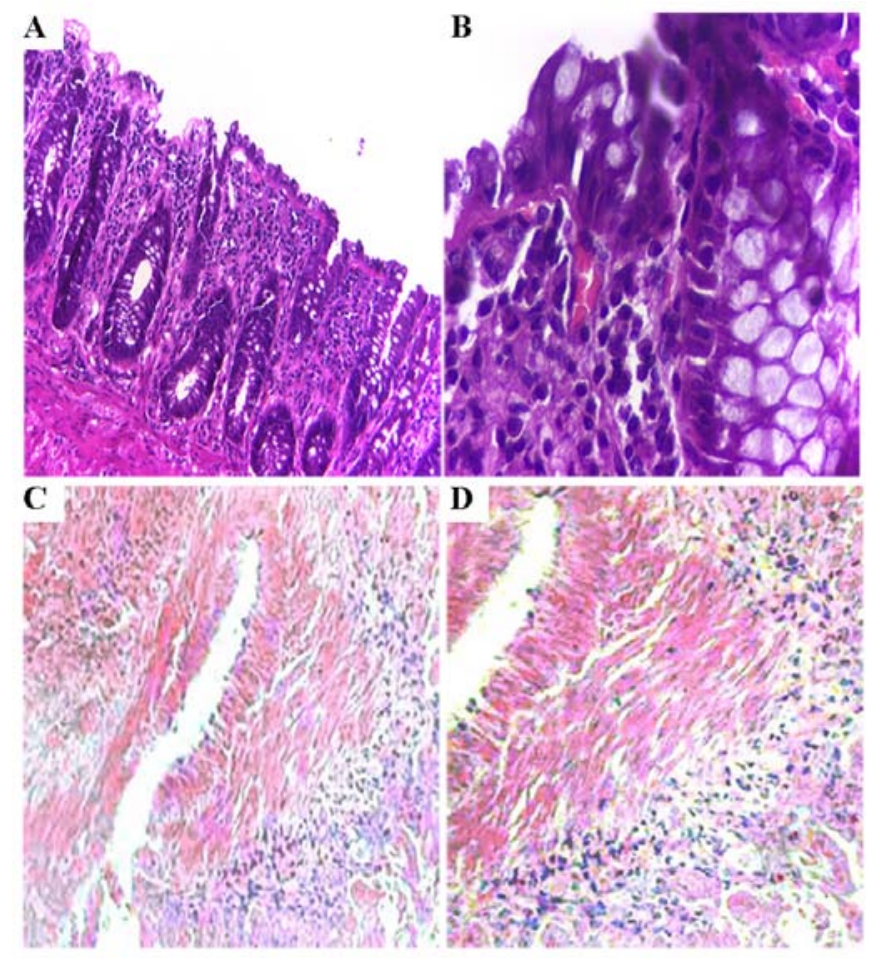

Figure 3. Structures of tissues exposed to TGF- $\beta 1$ for $48 \mathrm{~h}$ by H\&E staining. (A-D) Representive control and TGF- $\beta 1$-treated tissues, respectively. (A and C) Magnification, x100. (B and D) Magnification, x250.

in epithelial-mesenchymal transition (14) showing loss of epithelial markers such as E-cadherin, destruction of polarity and acquirement of mesenchymal markers such as vimentin and $\alpha$-SMA $(15,16)$. Therefore, E-cadherin, Crumbs 3 and $\alpha$-SMA were used as indicators in the present study. In the control, IHC analysis revealed that Crumbs 3 expression was mainly found in the apex of the epithelial membrane (Fig. 4E), E-cadherin expression was mainly noted in the epithelial layer of the mucosa and was positively associated with differentiation (Fig. 4F). $\alpha$-SMA expression with a monolayer was mainly along the crypt axis and slight expression was also found in the smooth muscle layer (Fig. 4G). By contrast, $48 \mathrm{~h}$ after exposure to TGF- $\beta 1$, expression of Crumbs 3 and E-cadherin in the tissues was mainly observed in the cytoplasm (Fig. 4A and B), while expression of $\alpha$-SMA was prominently found in activated myofibroblasts and mesenchyme (Fig. 4C). Furthermore, in addition to the altered location, in regards to quantification, the OD values of Crumbs3 (0.1005 \pm 0.0488$)$ and E-cadherin $(0.1967 \pm 0.0541)$ were significantly lower in the tissues treated with TGF- $\beta 1$ than the OD values in the control $(0.2706 \pm 0.0484$ and $0.2643 \pm 0.0192$, respectively; $\mathrm{P}<0.05$ ), while the $\alpha$-SMA level $(0.2957 \pm 0.0249)$ in the TGF- $\beta 1$ group was significantly higher than that noted in the control $(0.1867 \pm 0.0633$; $\mathrm{P}<0.01)$. However, after a $24-\mathrm{h}$ treatment with evodiamine and berberine, the tissues revealed higher growth viability, such as the existence of paved stone-like epithelial cells around the colon tissues. However, it was not determined whether evodiamine and berberine mediated the phenotypic changes induced by TGF- $\beta 1$. Hence, we detected the expression of phenotypic markers using qRT-PCR. As revealed in Fig. 4, the results showed that expression of Crumbs 3 in the TGF- $\beta 1$ 

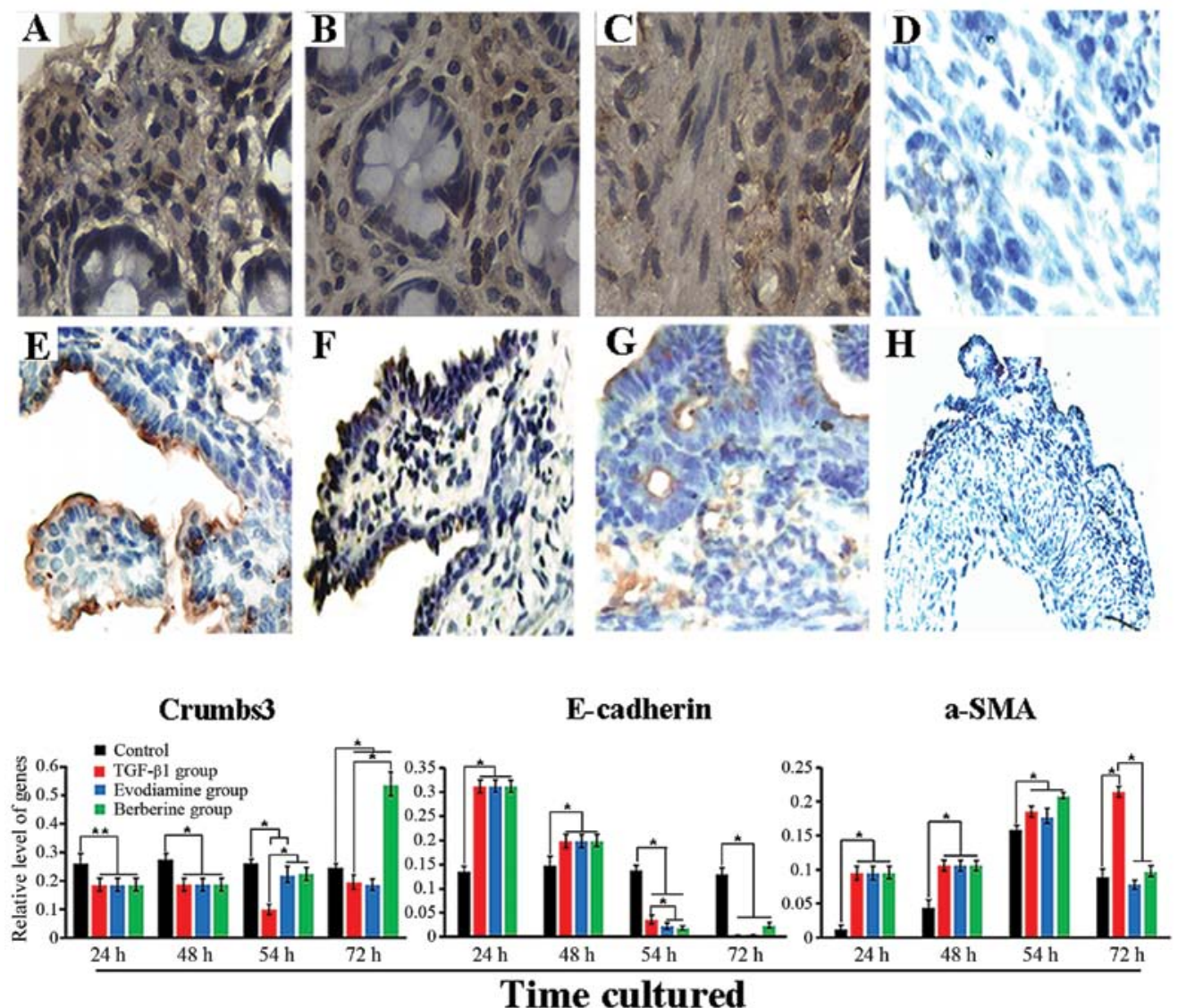

Figure 4. Immunohistochemical staining for tissues treated or not with $10 \mathrm{ng} / \mathrm{ml}$ TGF- $\beta 1$ for $48 \mathrm{~h}$ and qRT-PCR for Crumbs3, E-cadherin and $\alpha$-SMA. (A-C) Representive expression of Crumbs3, E-cadherin and $\alpha$-SMA in the TGF- $\beta 1$ group, respectively. (E-G) Representive expression levels in the control, respectively. (D and H) Negative control (magnification, $\mathrm{x} 400) .{ }^{*} \mathrm{P}<0.05$.

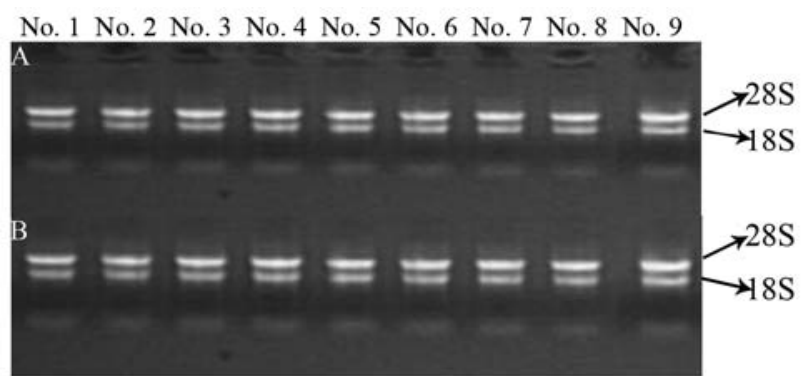

Figure 5. Electrophoretogram for RNA in the samples. (A and B) RNA quality of extracted DNMTs and microRNAs, respectively. No. 1, control group for 24 h; No. 2, TGF- 31 group for 24 h; No. 3, control group for 48 h; No. 4, TGF- $\beta 1$ group for 48 h; No. 5, control group for 72 h; No. 6, TGF- $\beta 1$ group for $72 \mathrm{~h}$; No. 7, berberine treatment for another $24 \mathrm{~h}$; No. 8 , evodiamine treatment for another $24 \mathrm{~h}$; and No. 9, 5-Aza-dC treatment for another $24 \mathrm{~h}$.

group was consistently lower than that of the control during culture $(\mathrm{P}<0.05)$, particularly at $54 \mathrm{~h}$. Twenty-four hours after stimulation with berberine, expression of Crumbs 3 was markedly different from that of the TGF- $\beta 1$ group and control $(\mathrm{P}<0.05)$. Unfortunately, its expression was lower in the evodiamine group than that noted in the TGF- $\beta 1$ group $(\mathrm{P}>0.05)$, which suggests that the biological effects of TGF- $\beta$ were reversed by evodiamine and berberine, particularly the latter. In addition, although there was no statistical significance, slightly upregulated E-cadherin was induced by evodiamine and berberine. Although there was no evident effect of evodiamine and berberine on $\alpha$-SMA expression following a 6-h treatment, its significant downregulation was noted after a 24-h stimulation $(\mathrm{P}<0.05)$, and its expression was close to a normal level compared to the control $(\mathrm{P}>0.05)$.

Expression of DNMTs and miRNAs as detected by RT-PCR pre-treatment and post-treatment

Sample RNA quality control. The integrity of RNA was assessed by electrophoresis on a denaturing agarose gel. Intact total RNA running on a denaturing gel had sharp 28S and $18 \mathrm{~S}$ rRNA bands (Fig. 5). The total RNAs of these samples had not been degraded and had adequate quality for the follow-up study.

TGF- $\beta 1$ upregulates the expression of DNMTs in the colon tissue. Two epigenetic regulatory factors, DNMTs and miRNAs, have pivotal roles in carcinogenesis and epigenetic modification $(17,18)$. To demonstrate whether upregulation or downregulation of DNMTs and target miRNAs occurs in a CRC canceration model induced by TGF- $\beta 1$, we performed quantitative RT-PCR analyses. Our results revealed that expression levels of DNMT1, DNMT3A and DNMT3B were $30.7 \%(\mathrm{P}<0.001), 57.49 \%(\mathrm{P}<0.001)$ and $60.26 \%(\mathrm{P}=0.0004)$, respectively, as compared with the control. After stimulation with TGF- $\beta 1$ for $24 \mathrm{~h}$, the relative expression of DNMT1 in the control and TGF- $\beta 1$ treatment group was $0.49044 \pm 0.02890$ 


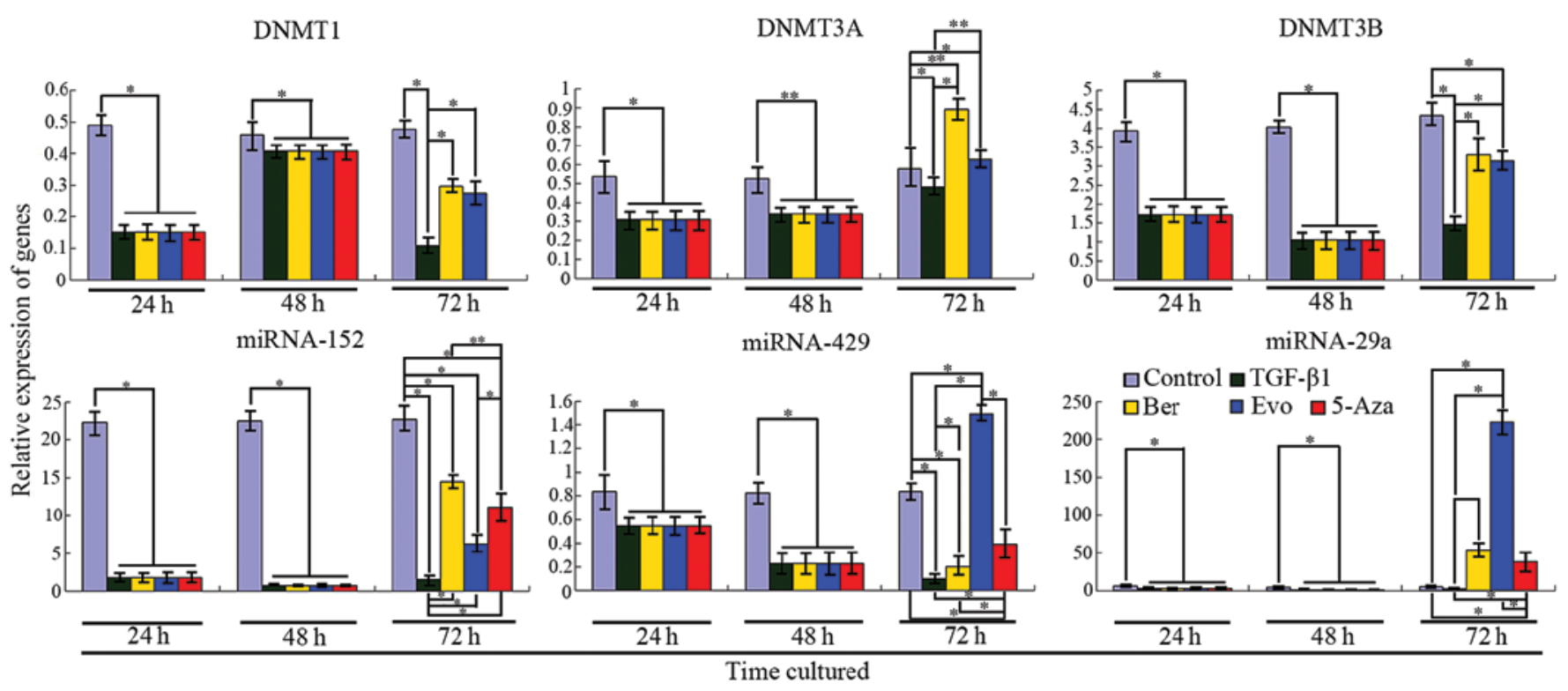

Figure 6. Expression profiles of DNMTs and target microRNAs during culture. The treatment groups but not the control were respectively treated with the 3 drugs (Ber, berberine; Evo, evodiamine; 5-Aza, 5-Aza-dC; ${ }^{*} \mathrm{P}<0.001,{ }^{* *} \mathrm{P}<0.05$ ) in the time period between 48 and $72 \mathrm{~h}$.

and $0.15064 \pm 0.0137$, respectively, and for DNMT3A the values were $0.53803 \pm 0.01410$ and $0.30929 \pm 0.02669$, respectively, and for DNMT3B, 3.94082 \pm 0.37565 and $1.71198 \pm 0.22057$, respectively. After treatment with TGF- $\beta 1$ for $48 \mathrm{~h}$, the expression levels of DNMT1, DNMT3A and DNMT3B were increased, but these levels were still lower than that of the control (Fig. 6). At this time, the relative expression of DNMT1 in the control and TGF- $\beta 1$ treatment group was $0.46046 \pm 0.04390$ and $0.40820 \pm 0.02852$, respectively, and for DNMT3A these values were $0.52721 \pm 0.04919$ and $0.3390 \pm 0.00727$, respectively, and for DNMT3B, 4.0348 \pm 0.05953 and $1.04989 \pm 0.19734$, respectively. 5-Aza-dC, an inhibitor of DNMTs, has been widely used in the clinic. After treatment with 5-Aza-dC, expression levels of the DNMTs were not detected by RT-PCR, suggesting that the activity of the DNMTs was fully inhibited, which lays a foundation for studying the regulation of target miRNAs by DNMTs.

Downregulation of microRNAs targeting DNMTs is induced by TGF- $\beta 1$ and reversed by DNMT inhibitor. miRNAs, the most widely studied class of non-coding RNAs (ncRNAs), mediate post-transcriptional gene silencing by inhibiting the translation of target mRNAs $(19,20)$. Recent studies concerning tumor miRNA expression profiles have displayed that the downregulation of miRNAs frequently exists in cancer tissues compared to their expression levels in normal tissue (21). Thus, in order to determine the expression profiles of miRNAs in colon carcinogenesis and whether these miRNAs mediate the expression of each DNMT gene, using the miRNA target prediction database (http://www.ebi.ac.uk/enright-srv/ microcosm/htdocs/targets/v5/, http://www.microrna.org/ microrna/home.do, http://mir-db.org/miRDB/), we detected the expression of the target miRNAs via qRT-PCR and used a DNMT inhibitor, 5-Aza-dC. Our results revealed (Fig. 6) that miRNA-29a, miRNA-152 and miRNA-429 were significantly downregulated after a 24 - and 48-h treatment with TGF- $\beta 1$, as compared with the control. However, these levels at $48 \mathrm{~h}$ were lower than those at $24 \mathrm{~h}$, which is consistent with a study of $\mathrm{Lu}$ et al (21). The relative expression of miRNA-152 (a target of DNMT1) in the control and TGF- $\beta 1$ treatment group following a 24 - and 48-h treatment was $22.28703 \pm 0.40663$, $1.78214 \pm 0.18116$ and $22.44430 \pm 0.03726,0.74761 \pm 0.31879$, respectively, and the relative expression of miRNA-429 (a target of DNMT3A) was $0.83347 \pm 0.06146,0.54788 \pm 0.02543$ and $0.82344 \pm 0.00379,0.22779 \pm 0.00867$, respectively, and the relative expression of miRNA-29a (a target of DNMT3A and DNMT3B) was 6.11961 $\pm 0.31352,2.90970 \pm 0.07024$ and $4.55873 \pm 0.50071,0.88628 \pm 0.02706$, respectively. When DNMT1, DNMT3A and DNMT3B were inhibited by 5-Aza$\mathrm{dC}$, notably, these target miRNAs were upregulated. These levels were still lower in the treatment group than that in the control. These results indicate that target miRNAs may serve as tumor suppressors during colon carcinogenesis and they can also be regulated by their corresponding DNMTs.

Berberine and evodiamine mediate the expression of DNMTs and target miRNAs. The results of the present study found that both berberine and evodiamine had an effect on the expression levels of DNMTs and target miRNAs (Fig. 6). Seventy-two hours after stimulation with TGF- $\beta 1$, qRT-PCR revealed that expression of DNMT1 in the berberine and evodiamine groups was $0.29639 \pm 0.07215$ and $0.27462 \pm 0.02630$, respectively, while its expression in the TGF- $\beta 1$ group was $0.10827 \pm 0.02736$, as compared with DNMT1 expression in the control (0.47688 \pm 0.06386$)$; for DNMT3A, $72 \mathrm{~h}$ after cultured with TGF- $\beta 1$, its expression in the two groups increased $(0.89135 \pm 0.08597$ and $0.62777 \pm 0.07734$, respectively), while its expression in the TGF- $\beta 1$ group increased as well $(0.48348 \pm 0.05992)$, but was lower than that of the two former groups and the control $(0.57838 \pm 0.09560)$. Consistent with 
the results for DNMT3A, $72 \mathrm{~h}$ later, expression of DNMT3B in the berberine, evodiamine, TGF- $\beta 1$ and control group was $3.29743 \pm 1.08786,3.13845 \pm 0.36048,1.44989 \pm 0.19734$ and $4.33481 \pm 0.31815$, respectively.

Since these DNMTs were affected by berberine and evodiamine, to determine whether the miRNAs were also influenced by the two drugs, we tested the expression levels of the target miRNAs by qRT-PCR. After a $24 \mathrm{~h}$ treatment with the drugs, expression of miRNA-152 (target of DNMT1) was higher in the berberine and evodiamine groups than that in the TGF- $\beta 1$ group, but lower than the control $(14.51982 \pm 3.25912$, $6.26986 \pm 1.41350,1.53881 \pm 0.29361$ and $22.65288 \pm 1.95338$, respectively). However, the expression profile of miRNA429 (target of DNMT3A) was not similar to that of DNMT1; its expression in the evodiamine group was upregulated (1.49523 \pm 0.02687$)$, but downregulated in the berberine and TGF- $\beta 1$ group $(0.20130 \pm 0.00671$ and $0.09948 \pm 0.00293$, respectively). In the presence of berberine and evodiamine, expression of miRNA-29a (target of DNMT3A and DNMT3B) in the berberine and TGF- $\beta 1$ group was markedly upregulated $(54.02511 \pm 3.59926$ and $2.53252 \pm 0.05201$, respectively), particularly its expression in the evodiamine group was significantly more than that of the control $(222.25954 \pm 5.46865$ vs. $5.19267 \pm 2.00633$ ). These results suggest that berberine and evodiamine influence the regulation of miRNAs targeting DNMTs.

\section{Discussion}

Accumulating evidence suggests that the development of colorectal cancer (CRC) involves a multistep process entailing the accumulation of genetic or epigenetic aberrations, which result in the simultaneous failure of protective mechanisms and the activation of tumorigenic pathways (22). Important findings of the present study were that expression levels of DNMT1, DNMT3A and DNMT3B, as well as their target microRNAs (miRNA-152, miRNA-429 and miRNA-29a) were markedly downregulated in the colon cancer tissues of the neonatal mice, as compared with the normal control, and that the target miRNAs were also regulated by DNMT1, DNMT3A and DNMT3B, respectively, and that both berberine and evodiamine had an effect on the expression of DNMTs and target miRNAs. These results indicate that both DNMTs and miRNAs are critical regulators of the initiation, growth and development of colon cancer in neonatal rats, and that berberine and evodiamine inhibited the onset and growth of colon cancer through epigenetics by influencing the expression of DNMTs and miRNAs. It is now known that epigenetic events involving multiple interactions with DNMTs, small non-coding RNAs and tumor-suppressor genes likely result in colon carcinogenesis. In the present study, we mainly focused on the inter-regulation between DNMTs and target miRNAs during colon canceration induced by TGF- $\beta 1$. As a major epigenetic modification, DNA methylation plays a critical role in the regulation of chromatin structure and gene expression and is involved in a variety of biological processes, as well as their levels and patterns are regulated by DNMT1, DNMT3A and DNMT3B (23). Epigenetic mechanisms can be promoted as a response to various stimuli and stressors subjected to the organism. Epigenetic modifications can be used as extraordinary candidates for new targets for drug development $(24,25)$. DNA methylation frequently occurs in the cytosine of $\mathrm{CpG}$ motifs methylated in the genome, but some regions called $\mathrm{CpG}$ islands in which the concentration of $\mathrm{CpG}$ motifs is abundant are usually demethylated. As such, the hypermethylation of such elements frequently leads to silencing or a downregulated expression of target genes. In contrast, their hypomethylation can contribute to the upregulation of gene expression. Numerous studies have found that global hypomethylation is associated with chromosomal instability and hypermethylation of key tumor-suppressor genes (TSGs) is used as a pivotal player in carcinogenesis $(26,27)$. In contrast, chromosomal instability playing a key role in CRC involves changes in the chromosome copy number and structure or the loss of the wild-type copy of TSGs, such as APC and TP53 (28). Unfortunately, these genes are frequently silenced in the process of colorectal canceration due to the hypermethylation of the promoter. Studies have revealed that overexpression of either DNMT3A or DNMT3B is related to carcinogenesis in a cancer type-dependent manner $(29,30)$, which suggests that both DNMT3A and DNMT3B play a pivotal role in canceration.

Together with the data mentioned above, our present results revealed that expression levels of the three DNMTs were downregulated in the TGF- $\beta 1$ group as compared with the normal control after a 24 -h treatment with TGF- $\beta 1$, while these genes were upregulated at $48 \mathrm{~h}$ after stimulation with TGF- $\beta 1$. This finding can be explained by the fact that various oncogenes may be activated or this is only a response to TGF- $\beta 1$ in the early phase of carcinogenesis. However, in the persistent presence of TGF- $\beta 1$, the expression levels of DNMT1 and DNMT3A were significantly increased indicating that hypermethylation occurred in promoter $\mathrm{CpG}$ islands, resulting in epigenetic silencing of TSGs leading to the generation and proliferation of neoplastic cells.

miRNAs, a cluster of small and non-coding RNAs of 18-23 nucleotides in length, regulate the expression of target genes post-transcriptionally and determine the cell fate by controlling the translation of target mRNAs in different tissues and cell types. Therefore, miRNAs take part in a variety of key biological processes involving cell growth, development, apoptosis, differentiation and oncogenesis by means of the regulation of gene expression (31). miRNA-429 mainly targets DNMT3A while targets of miRNA-29a include DNMT3A and DNMT3B. Downregulation of miRNA-29a whose level is associated with prognosis (32) was found in various tumors such as liver (33) and lung (34). DNMT1 can be targeted by miR-152 (35) whose downregulation was also observed in many types of cancers, such as ovarian (36), stomach and breast cancer $(37,38)$. miRNAs whose positive and negative regulation has been described in colorectal carcinogenesis are deemed as potential molecular biomarkers for human malignancies $(39,40)$. Our results in the present study revealed that expression levels of miR-152, miR-429 and miR-29a were continuously downregulated after treatment with TGF- $\beta 1$, indicating that these miRNAs may play a role as tumor suppressors and are inactivated during colon carcinogenesis. Taken together, the expression profiles of the DNMTs determined that expression levels of the DNMTs were negatively regulated by their target miRNAs. The underlying mechanisms 
that contributed to the regulation of the DNMTs by target miRNAs have been addressed. A recent study demonstrated that miRNAs downregulate DNMT3B expression by directly targeting the 3'-UTR of DNMT3B mRNA (18). Our data indicated that miR-152, miR-429 and miR-29a directly bind to the DNMT1, DNMT3A and DNMT3B transcript, respectively, and post-transcriptionally mediate expression of those genes. In addition, after treatment with 5-Aza-dC, expression of these target miRNAs was markedly increased but did not reach a normal level, revealing that the expression of miRNAs was also regulated by their corresponding DNMTs. In this context, there is crucial crosstalk between DNMTs and target miRNAs through a double-negative feedback loop.

Berberin, an isoquinoline alkaloid (41), is extracted from the Chinese herbal medicine Coptis chinensis, and has been found to have multiple antitumor roles which are valuable in clinical treatment. Recent results have demonstrated that berberin inhibited the proliferation of colon cancer cells through downregulation of epidermal growth factor receptor (EGFR) expression (42), suppressed colon cancer cell migration by targeting AMP-activated protein kinase (AMPK) signaling (43), and induced cancer cell death via cell cycle arrest, inducing apoptosis and inhibiting inflammation (44). Evodiamine, a natural chemical isolated from Evodia rutaecarpa, shows numerous biological effects including antitumor, antinociceptive and vasorelaxant properties $(45,46)$. Recent results demonstrated that the viability of CRC cells can be inhibited by evodiamine via induction of apoptosis (47).

Although pharmacological research of berberine and evodiamine has been carried out, studies concerning their effect on epigenetic alterations is sparse. Our present results revealed that berberine and evodiamine had a prominent effect on expression of DNMTs and target miRNAs during early colon canceration as compared with TGF- $\beta$ group. In particular, their effect on the expression of miR-29a was more obvious, implying that berberine and evodiamine mediate the expression of DNMTs and miRNAs by a mechanism involving the targeting of multiple factors which warrant further elucidation. Our results suggest that berberine and evodiamine are potential therapeutic agents for the early treatment and prevention of CRC.

\section{Acknowledgements}

The present study was funded by the National Natural Science Foundation of China (no. 81173257).

\section{References}

1. Tenesa A and Dunlop MG: New insights into the aetiology of colorectal cancer from genome-wide association studies. Nat Rev Genet 10: 353-358, 2009.

2. Friess H, Langrehr JM, Oettle H, Raedle J, Niedergethmann M, Dittrich C, Hossfeld DK, Stöger H, Neyns B, Herzog P, et al: A randomized multi-center phase II trial of the angiogenesis inhibitor cilengitide (EMD 121974) and gemcitabine compared with gemcitabine alone in advanced unresectable pancreatic cancer. BMC Cancer 6: 285, 2006.

3. Philip PA, Benedetti J, Corless CL, Wong R, O'Reilly EM, Flynn PJ, Rowland KM, Atkins JN, Mirtsching BC, Rivkin SE, et al: Phase III study comparing gemcitabine plus cetuximab versus gemcitabine in patients with advanced pancreatic adenocarcinoma: Southwest Oncology Group-directed intergroup trial S0205. J Clin Oncol 28: 3605-3610, 2010.
4. van Kampen JG, Marijnissen-van Zanten MA, Simmer F, van der Graaf WT, Ligtenberg MJ and Nagtegaal ID: Epigenetic targeting in pancreatic cancer. Cancer Treat Rev 40: 656-664, 2014.

5. Garagnani P, Pirazzini C and Franceschi C: Colorectal cancer microenvironment: Among nutrition, gut microbiota, inflammation and epigenetics. Curr Pharm Des 19: 765-778, 2013.

6. Postovit LM, Seftor EA, Seftor RE and Hendrix MJ: Influence of the microenvironment on melanoma cell fate determination and phenotype. Cancer Res 66: 7833-7836, 2006.

7. Adjei IM and Blanka S: Modulation of the tumor microenvironment for cancer treatment: A biomaterials approach. J Funct Biomater 6: 81-103, 2015.

8. Shi $X$ and Wang X: The role of MTDH/AEG-1 in the progression of cancer. Int J Clin Exp Med 8: 4795-4807, 2015.

9. $\mathrm{Ma} \mathrm{H}, \mathrm{Xu} \mathrm{H}$ and Qin J: Biomimetic tumor microenvironment on a microfluidic platform. Biomicrofluidics 7: 11501, 2013.

10. Schmaus A, Bauer J and Sleeman JP: Sugars in the microenvironment: The sticky problem of HA turnover in tumors. Cancer Metastasis Rev 33: 1059-1079, 2014.

11. Hanahan D and Weinberg RA: Hallmarks of cancer: The next generation. Cell 144: 646-674, 2011.

12. Zu X, Zhang Q, Cao R, Liu J, Zhong J, Wen G and Cao D: Transforming growth factor- $\beta$ signaling in tumor initiation, progression and therapy in breast cancer: An update. Cell Tissue Res 347: 73-84, 2012.

13. Neuzillet C, Tijeras-Raballand A, Cohen R, Cros J, Faivre S, Raymond $\mathrm{E}$ and de Gramont A: Targeting the TGF $\beta$ pathway for cancer therapy. Pharmacol Ther 147: 22-31, 2015.

14. Ohshio Y, Teramoto K, Hashimoto M, Kitamura S, Hanaoka J and Kontani K: Inhibition of transforming growth factor- $\beta$ release from tumor cells reduces their motility associated with epithelialmesenchymal transition. Oncol Rep 30: 1000-1006, 2013.

15. Mao Y, Keller ET, Garfield DH, Shen K and Wang J: Stromal cells in tumor microenvironment and breast cancer. Cancer Metastasis Rev 32: 303-315, 2013.

16. Quante M, Varga J, Wang TC and Greten FR: The gastrointestinal tumor microenvironment. Gastroenterology 145: 63-78, 2013.

17. Lee JY, Jeong W, Lim W, Lim CH, Bae SM, Kim J, Bazer FW and Song G: Hypermethylation and post-transcriptional regulation of DNA methyltransferases in the ovarian carcinomas of the laying hen. PLoS One 8: e61658, 2013.

18. Xue G, Ren Z, Chen Y, Zhu J, Du Y, Pan D, Li X and Hu B: A feedback regulation between miR-145 and DNA methyltransferase $3 \mathrm{~b}$ in prostate cancer cell and their responses to irradiation. Cancer Lett 361: 121-127, 2015.

19. He L and Hannon GJ: MicroRNAs: Small RNAs with a big role in gene regulation. Nat Rev Genet 5: 522-531, 2004.

20. Mendell JT: MicroRNAs: Critical regulators of development, cellular physiology and malignancy. Cell Cycle 4: 1179-1184, 2005.

21. Lu J, Getz G, Miska EA, Alvarez-Saavedra E, Lamb J, Peck D, Sweet-Cordero A, Ebert BL, Mak RH, Ferrando AA, et al: MicroRNA expression profiles classify human cancers. Nature 435: 834-838, 2005.

22. Vaiopoulos AG, Athanasoula KCh and Papavassiliou AG: NF- $\kappa B$ in colorectal cancer. J Mol Med 91: 1029-1037, 2013.

23. Hamidi T, Singh AK and Chen T: Genetic alterations of DNA methylation machinery in human diseases. Epigenomics 7: 247-265, 2015.

24. Cea M, Cagnetta A, Gobbi M, Patrone F, Richardson PG, Hideshima T and Anderson KC: New insights into the treatment of multiple myeloma with histone deacetylase inhibitors. Curr Pharm Des 19: 734-744, 2013.

25. Andreoli F, Barbosa AJ, Parenti MD and Del Rio A: Modulation of epigenetic targets for anticancer therapy: Clinicopathological relevance, structural data and drug discovery perspectives. Curr Pharm Des 19: 578-613, 2013.

26. Esteller M: Epigenetics in cancer. N Engl J Med 358: 1148-1159, 2008.

27. Laird PW: The power and the promise of DNA methylation markers. Nat Rev Cancer 3: 253-266, 2003.

28. Markowitz SD and Bertagnolli MM: Molecular origins of cancer: Molecular basis of colorectal cancer. N Engl J Med 361: 2449-2460, 2009.

29. Wu Q and Ni X: ROS-mediated DNA methylation pattern alterations in carcinogenesis. Curr Drug Targets 16: 13-19, 2015.

30. Luczak MW and Jagodziński PP: The role of DNA methylation in cancer development. Folia Histochem Cytobiol 44: 143-154, 2006. 
31. Pastuszak-Lewandoska D, Kordiak J, Migdalska-Sek M CzarneckaKH,Antczak A,Górski P, NawrotE,KiszałkiewiczJM, Domańska D and Brzeziańska-Lasota E: Quantitative analysis of mRNA expression levels and DNA methylation profiles of three neighboring genes: FUS1, NPRL2/G21 and RASSF1A in non-small cell lung cancer patients. Respir Res 16: 76, 2015.

32. Garzon R, Fabbri M, Cimmino A, Calin GA and Croce CM: MicroRNA expression and function in cancer. Trends Mol Med 12: 580-587, 2006

33. Xiong Y, Fang JH, Yun JP, Yang J, Zhang Y, Jia WH and Zhuang SM: Effects of microRNA-29 on apoptosis, tumorigenicity, and prognosis of hepatocellular carcinoma. Hepatology 51 836-845, 2010

34. Fabbri M, Garzon R, Cimmino A, Liu Z, Zanesi N, Callegari E, Liu S, Alder H, Costinean S, Fernandez-Cymering C, et al: MicroRNA-29 family reverts aberrant methylation in lung cancer by targeting DNA methyltransferases $3 \mathrm{~A}$ and 3B. Proc Natl Acad Sci USA 104: 15805-15810, 2007.

35. Xu H, Cheung IY, Guo HF and Cheung NK: MicroRNA miR-29 modulates expression of immunoinhibitory molecule B7-H3: Potential implications for immune based therapy of human solid tumors. Cancer Res 69: 6275-6281, 2009.

36. Ji W, Yang L, Yuan J, Yang L, Zhang M, Qi D, Duan X, Xuan A, Zhang W, Lu J, et al: MicroRNA-152 targets DNA methyltransferase 1 in NiS-transformed cells via a feedback mechanism. Carcinogenesis 34: 446-453, 2013.

37. Langhe R, Norris L, Saadeh FA, Blackshields G, Varley R, Harrison A, Gleeson N, Spillane C, Martin C, O'Donnell DM, et al: A novel serum microRNA panel to discriminate benign from malignant ovarian disease. Cancer Lett 356: 628-636, 2015.

38. Pinto R, De Summa S, Danza K, Popescu O, Paradiso A Micale L, Merla G, Palumbo O, Carella M and Tommasi S: MicroRNA expression profiling in male and female familial breast cancer. Br J Cancer 111: 2361-2368, 2014.

39. Omrane I and Benammar-Elgaaied A: The immune microenvironment of the colorectal tumor: Involvement of immunity genes and microRNAs belonging to the TH17 pathway. Biochim Biophys Acta 1856: 28-38, 2015 .
40. Slaby O, Svoboda M, Michalek J and Vyzula R: MicroRNAs in colorectal cancer: Translation of molecular biology into clinical application. Mol Cancer 8: 102, 2009.

41. Chen C, Yu Z, Li Y, Fichna J and Storr M: Effects of berberine in the gastrointestinal tract - a review of actions and therapeutic implications. Am J Chin Med 42: 1053-1070, 2014.

42. Wang L, Cao H, Lu N, Liu L, Wang B, Hu T, Israel DA, Peek RM Jr, Polk DB and Yan F: Berberine inhibits proliferation and down-regulates epidermal growth factor receptor through activation of Cbl in colon tumor cells. PLoS One 8: e56666, 2013.

43. Park JJ, Seo SM, Kim EJ, Lee YJ, Ko YG, Ha J and Lee M: Berberine inhibits human colon cancer cell migration via AMP-activated protein kinase-mediated downregulation of integrin $\beta 1$ signaling. Biochem Biophys Res Commun 426: 461-467, 2012.

44. Chidambara Murthy KN, Jayaprakasha GK and Patil BS: The natural alkaloid berberine targets multiple pathways to induce cell death in cultured human colon cancer cells. Eur J Pharmacol 688: 14-21, 2012.

45. Kan SF, Yu CH, Pu HF, Hsu JM, Chen MJ and Wang PS: Anti-proliferative effects of evodiamine on human prostate cancer cell lines DU145 and PC3. J Cell Biochem 101: 44-56, 2007.

46. Kobayashi Y: The nociceptive and anti-nociceptive effects of evodiamine from fruits of Evodia rutaecarpa in mice. Planta Med 69: 425-428, 2003.

47. Chien CC, Wu MS, Shen SC, Ko CH, Chen CH, Yang LL and Chen YC: Activation of JNK contributes to evodiamine-induced apoptosis and $\mathrm{G}_{2} / \mathrm{M}$ arrest in human colorectal carcinoma cells: A structure-activity study of evodiamine. PLoS One 9: e99729, 2014. 